\title{
Surgery for the obese
}

\author{
N. Amjad \\ Professor of Surgery, Deputy Dean of Research, International Islamic University of Medicine \\ Kuantan, Malaysia.
}

Key words : Bariatric surgery; weight loss; malabsorptive; restrictive.

\begin{abstract}
This review focuses on the problem of obesity from an Asian perspective and the current evidence that supports the benefits of bariatric surgery over conventional treatment for sustained weight loss. The requirements for an effective bariatric surgical service are highlighted. Principles of peri-operative management and the currently practiced operative procedures are discussed briefly. Finally a short evaluation of the benefits and complication of the different procedures are presented.
\end{abstract}

\section{Introduction}

Obesity is a global epidemic and its increasing prevalence worldwide is a major public health issue. Although initially restricted to developed, high-income countries, with the advent of globalization it has engulfed the low and middle-income states as well. According to WHO estimates, by the year 2015, an estimated 700 million adults will be diagnosed as obese [1]. Most Asian countries too face this dilemma. Rapid economic growth in Asia over the last few decades has resulted in an increase in the prevalence of overweight individuals although wide differences exist between countries [2,3]. Mostly confined to urban populations, the improving socio-economic conditions in Asia have resulted in an increase in semi urban and rural areas now [4]. South Asians seem to have the highest prevalence of abdominal obesity [5]. In a study involving 4532 adults, the prevalence of overweight and obesity among Sri Lankan adults were 25.2 percent and 9.2 percent while central obesity was found in 26.2 percent [6]. According to Wijewardene et al, the prevalence of obesity related

Correspondence: N.Amjad

E-mail:jadnm@hotmail.com metabolic problems such as diabetes and hypertension among Sri Lankan adults were 14 and 19 percent respectively [7].

\section{Role of bariatric surgery}

The financial burden on a developing country like ours is immense with regard to the treatment of morbid obesity and its related co-morbidity. It is imperative that health professionals identify the most cost effective and sustainable mode of treatment. Non-surgical measures like dieting, exercise, and cognitive behavioural therapy achieve long-term weight loss in only a small minority of highly motivated individuals [8].

The ultimate objective in the management of morbid obesity is long-term weight loss and the current consensus on the most effective modality to achieve this goal is surgical management. A recent meta- analysis of 11 studies involving 796 obese patients with a body mass index (BMI) between 30 to $52 \mathrm{Kg} / \mathrm{m} 2$ showed that patients who underwent surgical treatment, on average, lost more weight than those who tried other means (95\% CI. 21 to $31 \mathrm{~kg}$ lost; $\mathrm{P}<0.001$ ). This was accompanied with significant improvement in their diabetes status and metabolic syndrome, (relative risk 22.1-3.2 to 154.3; $\mathrm{P}=0.002$ ) and (relative risk 2.4-1.6 to 3.6; $\mathrm{P}<0.001$ ) respectively [9]. Improvements were also noted in their lipid profiles and more importantly quality of life [9]. Mingrone et al also demonstrated a significantly better glucose control by surgery than medical management in the patient with severely obese type 2 diabetes [10]. The landmark Swedish Obese Subjects (SOS) study, the first long-term, prospective, controlled trial confirms bariatric surgery to be associated with significant long-term reduction in overall mortality (primary endpoint) and decreased incidences of diabetes, myocardial infarction, stroke and cancer. The diabetes remission rate was increased several fold at 2 years and 10 years [11]. Thus, current 
Table 1: Recommended Indications for bariatric surgery in the asian population

\begin{tabular}{|c|c|}
\hline Indications based on BMI [13] & Other Indications [14] \\
\hline 1. BMI more than 35 with or without co-morbidity & $\begin{array}{l}\text { 1. Age between } 16 \text { and } 65 \text { years } \\
\text { 2. Documented failure at non surgical approaches to long- } \\
\text { term weight loss }\end{array}$ \\
\hline 2. BMI of 32 with co-morbidity & $\begin{array}{l}\text { 3. Acceptable operative risks } \\
\text { 4. A well-informed and motivated patient }\end{array}$ \\
\hline $\begin{array}{l}\text { 3. BMI of } 30 \text { if they have central obesity along with at } \\
\text { least two of the additional criteria for metabolic } \\
\text { syndrome }\end{array}$ & $\begin{array}{l}\text { 5. Commitment to prolonged lifestyle changes } \\
\text { 6. Supportive family/social environment } \\
\text { 7. Resolution of alcohol or substance abuse }\end{array}$ \\
\hline $\begin{array}{l}\text { 4. BMI less than } 30 \text { - should be strictly done only } \\
\text { under study protocol with an informed consent from } \\
\text { the patient }\end{array}$ & $\begin{array}{l}\text { 8. A psychologically stable patient with realistic expectations } \\
\text { 9. Absence of active psychosis and untreated severe } \\
\text { depression }\end{array}$ \\
\hline
\end{tabular}

evidence supports surgical treatment for obesity.

\section{Indications for surgery}

Available data do not indicate a clear BMI cut-off point which defines overweight in Asians and seem to vary from 22 to 25 in different Asian populations [12]. The currently accepted figures are $23,27.5,32.5$, and 37.5 for overweight, obesity 1 , obesity 2 , and morbid obesity respectively. (Table 1)

\section{Preoperative preparation}

Obese patients are high risk surgical candidates and other modalities of management must be exhausted prior to offering surgery. The obesity multi disciplinary team (MDT) comprising of nutritionists, anaesthesiologists, cardiologist, respiratory physicians, orthopaedic surgeons, endocrinologists, psychiatrists and specialists in rehabilitation medicine must be involved in the decision making process. Once the choice is made to offer surgery, it is the role of the MDT to make the patient aware of the expected permanent changes to his or her lifestyle following these procedures. Major changes involving dietary habits, bowel symptoms and physical activity must be emphasized.

\section{Counseling}

Preoperative counseling is crucial and should be carried out by a counselor, psychologist, or psychiatrist who is familiar with current trends in the management of obesity. These patients tend to have higher levels of stress, anxiety, depression, food craving and lower levels of self-esteem and quality of life compared with controls with normal weight [15]. Pre-operative evaluation also helps to identify patients with latent psychiatric disorders (e.g. major depression, schizophrenia, antisocial personality disorder) so that necessary therapy could be instituted and the individual re-evaluated prior to surgery. Presence of psychological disorders is not a contraindication except in the case of serious disorders such as active suicidal ideation, hallucinations and/or delusions, or severe cognitive impairment. Psychiatric evaluation also determines, in an objective manner, the ability of the patient to make major lifestyle changes for a successful outcome.

\section{Anaesthetic assessment}

Preoperative anaesthetic evaluation must focus on both physical status of patients and comorbidity that could impact the course and outcome of the procedure. A complete history and physical examination is carried out to assess suitability for a major surgical operation. Adequate control of previously identified comorbidity like hypertension and diabetes mellitus and undiagnosed obesity related pathology such as obstructive sleep apnea (OSA) must be excluded. This is not uncommon as was demonstrated by Nepomnayshy et al in a study of 882 morbidly obese patients screened for sleep apnea prior to bariatric surgery, where they identified an additional 25 percent of patients with OSA [16]. Obese patients should be evaluated for predictors of both difficult mask ventilation and difficult intubation, as additional equipment and skilled personnel should be readily available if necessary. Studies show that BMI on its own is not a predictor of difficult tracheal intubation, whereas large neck circumference $(>40 \mathrm{~cm})$, Mallampati score $\geq 3$ and thyromental distance $<6 \mathrm{~cm}$ are more specific indicators of potential difficulty [17]. These patients tend to desaturate more quickly during periods of apnea than 
non-obese patients.

\section{Operating theatre facilities}

Furthermore, hospitals must possess the infrastructure to support bariatric surgery, including rooms with wider doorways and special furniture that would support the extra weight of patients. Especially designed operating tables are recommended. Trolleys to transport patients must be suitably equipped.

\section{Choice of surgical approach}

Rapid advancement in minimally invasive surgery since the 1990s has lead to laparoscopic bariatric surgery being widely practiced now. It gives excellent access to the hiatus and proximal stomach in the head-up position. Standard laparoscopic instruments are not suitable for bariatric work. Open Hasson's technique is not recommended for pneumoperitoneum, as the abdominal wall in these patients can be several inches thick. Instead, Veress needle insertion in the left upper quadrant is preferred. Some surgeons utilize an optical trocar but this technique needs experience for safe practice [18]. Difficulties in trocar insertion for working ports can be encountered due to the thick abdominal wall. Specially designed longer ports must be used. The same applies to instruments and stapling devices, as they too must be longer than the standard instruments used in upper gastro-intestinal surgery.

Surgeons undertaking bariatric surgery must be familiar with the technical issues if the need arises to perform open surgery either by choice or due to conversion from a laparoscopic procedure. This is especially relevant in patients with central obesity and patients with large fatty liver. Retraction is one of the main impediments and may require a dedicated "Omnitract" system with deepbladed retractors. Adequate measures must be undertaken in the closure of the abdominal incision, as the incidence of incisional hernia may be as high as 18.7 percent at 2years after open surgery [19].

Laparoscopic bariatric surgery is associated with significant shorter recovery time and reduced 30 daymorbidity rates [20]. Data from the United States indicate an increase in laparoscopic bariatric surgery from 20 to 90 percent between 2003 and 2008. During the same period there was a decrease in in-hospital mortality from 0.21 percent in 2003 to 0.10 percent in 2008 [21]. Recent reports from Asia too indicate a dramatic increase in bariatric surgery by almost 449 percent between 2005 and 2009 [22].

\section{Peri-operative care}

Most obese patients with uncomplicated medical comorbidity can be managed post-operatively in the standard surgical unit with adequate monitoring. It includes monitoring of fluid intake and output; drain output if any and clinical evaluation for possible anastomotic leak. Initially, patients are kept "nil by mouth" and subsequently commenced on clear liquids and then advanced to a high-protein liquid diet. Limiting intensive care admission to patients with a BMI $>60$ and severe OSA do not show any significant increase in the overall incidence of postoperative respiratory complications or length of hospital stay [23].

Following the introduction of a structured protocol based bariatric surgery service in the United States, a review of 98,553 bariatric surgical patients for hospital acquired conditions HACs: surgical site infection (SSI), urinary tract infection (UTI), and venous thromboembolism (VTE), demonstrated a significant drop in the rate of HACs from 4.6 percent in 2005-06 to 2.5 percent in 2012 [24]. Another similar study concluded that a bariatric surgery clinical protocol is feasible and safe with substantial cost savings due to low patient re-admission and complication rates [25].

\section{Treatment}

Hendrickson performed the first bariatric surgical procedure back in the 1950s; it was an extensive small bowel resection, which led to malabsorptive weight loss [26]. The practice remained dormant until the discovery of the relationship between obesity and metabolic syndrome. With the subsequent explosion of the obesity epidemic, bariatric surgery has been widely recognized as the most effective and well-researched modality. It must also be emphasized that surgical intervention is final; it can have dangerous long-term effects, which can lead to a life-long dependency on medical assistance. Due to limitations of infrastructure, expertise and cost, only a minority of eligible candidates are able to undergo bariatric surgery. Even in the United States only an estimated 1percent of patients who are eligible receive bariatric surgery in any given year [27].

The basic principle of obesity surgery is to reduce caloric intake and is undertaken by changing the 
Table 2- The standard bariatric procedures

\begin{tabular}{|l|l|l|}
\hline \multicolumn{1}{|c|}{ Purely restrictive } & \multicolumn{1}{|c|}{ Purely malabsorbtive } & \multicolumn{1}{c|}{ Combined } \\
\hline $\begin{array}{l}\text { Laparoscopic gastric banding } \\
\text { (LAGB) } \\
\begin{array}{l}\text { Sleeve gastrectomy (LSG) } \\
\text { Vertical banded gastroplasty } \\
\text { (VBG) }\end{array}\end{array}$ & $\begin{array}{l}\text { Jejunoileal bypass } \\
\text { Duodenal switch }\end{array}$ & $\begin{array}{l}\text { Roux-en-y gastric bypass (RYGB) } \\
\text { Bilio-pancreatic diversion (BPD) with or } \\
\text { without duodenal switch }\end{array}$ \\
\hline $\begin{array}{l}\text { Decreases the stomach capacity } \\
\text { leading to reduced food intake } \\
\text { Produce more gradual weight loss }\end{array}$ & $\begin{array}{l}\text { Reduces nutrient absorption due to a } \\
\text { shortened functional small bowel }\end{array}$ & $\begin{array}{l}\text { Creation of a small gastric pouch, thereby } \\
\text { restricting food }\end{array}$ \\
Good weight reduction & $\begin{array}{l}\text { Malabsorptive component limiting caloric } \\
\text { absorption }\end{array}$ \\
\hline
\end{tabular}

anatomy of the gastrointestinal tract. This alters the gut-brain axis peptides, by increasing anorexigenic gut hormones such as peptide YY from the small bowel, and a reduction in the orexigenic hormone, ghrelin - mainly produced in the fundus of the stomach [28]. The mechanisms utilized to achieve this involve malabsorption, restriction or a combination of the two.(Table 2)

The surgeon in consultation with the MDT and the patient will propose the surgical options. This must be based firstly on the merits of the procedure for the patient's BMI (and comorbidity), and secondly on the patient's preference.

\section{Surgical procedures}

\section{Laparoscopic adjustable gastric band (LAGB)}

This was a popular procedure up until a few years ago and was promoted as a safe and reversible procedure. It was perceived to be a simple procedure with lower complication rates when compared with the more established procedures. The degree of restriction can be varied if required by altering the band volume [29]. Currently available popular brands are the Lap- band $\mathbb{}$ System and the Swedish adjustable band.

This is carried out by placing a band around the proximal stomach approximately $2 \mathrm{~cm}$ distal to the gastro-oesophageal junction. (Figure 1) The aim is to create a $25-30 \mathrm{ml}$ upper gastric pouch and the band is fixed to prevent slippage. The balloon in the band is connected to the subcutaneous port and can be varied by injecting saline via the tubing as shown in the picture

LAGB has shown to have high rates of intermediate

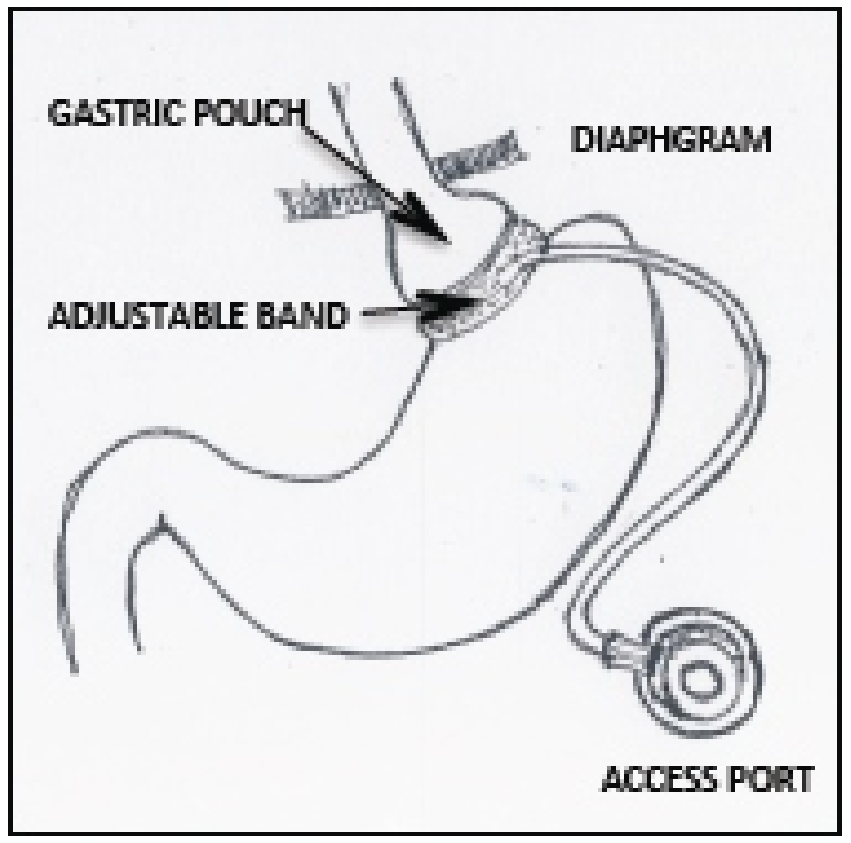

Figure 1. Laparoscopic adjustable gastric band (LAGB)

(band erosion or slippage) and long-term complications (failure to achieve or maintain weight loss) requiring reoperation in up to 20 percent of patients [30]. There are conflicting reports as some centres show very good long-term results. A durable weight loss with 47 percent excess weight loss (EWL) maintained to 15 years was demonstrated in a prospective longitudinal cohort study of 3227 LAGB patients. This weight loss occurred regardless of whether any revisional procedures were needed [31]. Despite this, surgeons are now opting for laparoscopic roux-en-y gastric bypass resulting in fewer LAGB procedures being performed [32].

\section{Roux-en-Y gastric bypass (RYGB)}

RYGB is the gold standard bariatric procedure in the United States, accounting for 93 percent of all such 
operations in 2000 [33]. This is also the commonest operation worldwide because it combines both components of weight reduction surgery in one procedure, and since Mason first performed the procedure in the $1960 \mathrm{~s}$, there have been multiple revisions to the procedure [34]. At present, most of these procedures are performed laparoscopically. The stomach is restricted by creating a $25-30 \mathrm{ml}$ proximal gastric pouch. (Figure 2) The pouch is divided and separated from the distal stomach. The small intestine is divided at about 30 to $50 \mathrm{~cm}$ distal to the ligament of Treitz. The roux limb (or alimentary limb) is anastomosed to the gastric pouch.

The divided biliopancreatic limb is anastomosed to the roux limb approximately $150 \mathrm{~cm}$ distal to the gastrojejunostomy. Most digestion and absorption of nutrients occurs distal to this anatomosis. Variations in technique have focused on optimization of the length of the roux limb to achieve the best balance between weight reduction and complications of altered gastrointestinal anatomy and physiology.

Studies have shown suppression of pulsatile release of the orexigenic hormone and increase in levels of the anorectic hormones glucagon-like peptide-1 (GLP-1) and cholecystokinin (CCK) after gastric bypass $[35$, 36].

This procedure produces better weight loss compared to purely restrictive operations but has many complications. Most significant of these are stomach

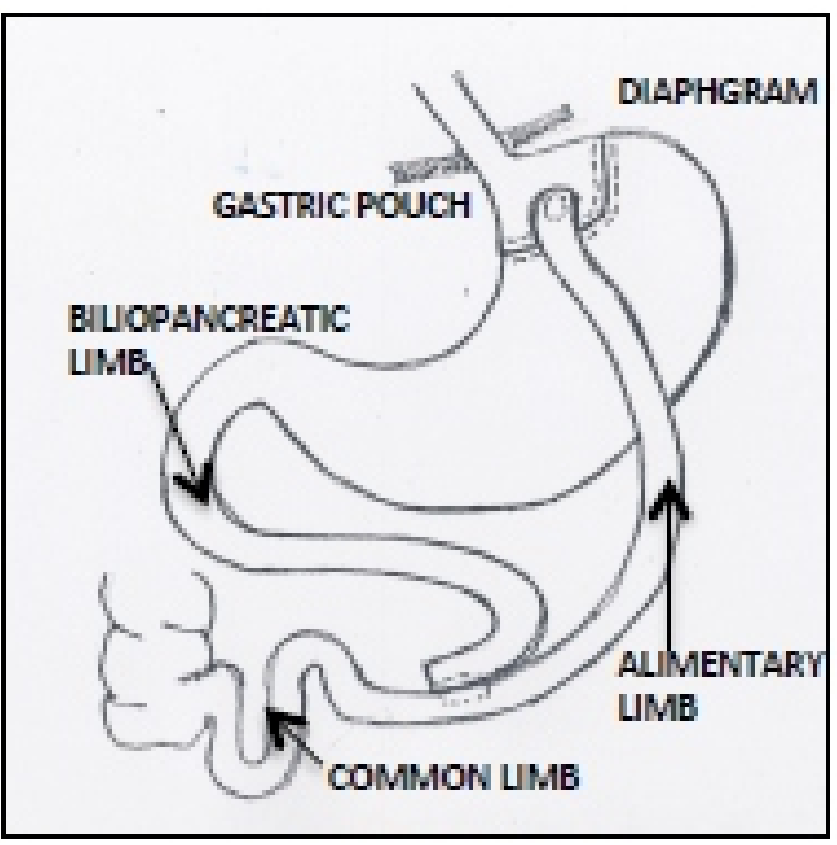

Figure 2. Roux-en-Y gastric bypass (RYGB) ulcers that necessitate prophylactic ulcer therapy. Also, vitamin and mineral deficiencies may need lifelong supplementation.

\section{Laparoscopic sleeve gastrectomy (LSG)}

LSG has gained popularity and acceptance among bariatric surgeons, mainly due its low morbidity and mortality. Sleeve gastrectomy is a restrictive procedure. A vertical resection of the stomach is performed, in which the majority of the greater curvature is removed and a long tubular stomach defined by a bougie lying against the lesser curve is created.The pylorus and part of the antrum are preserved. (Figure 3 )

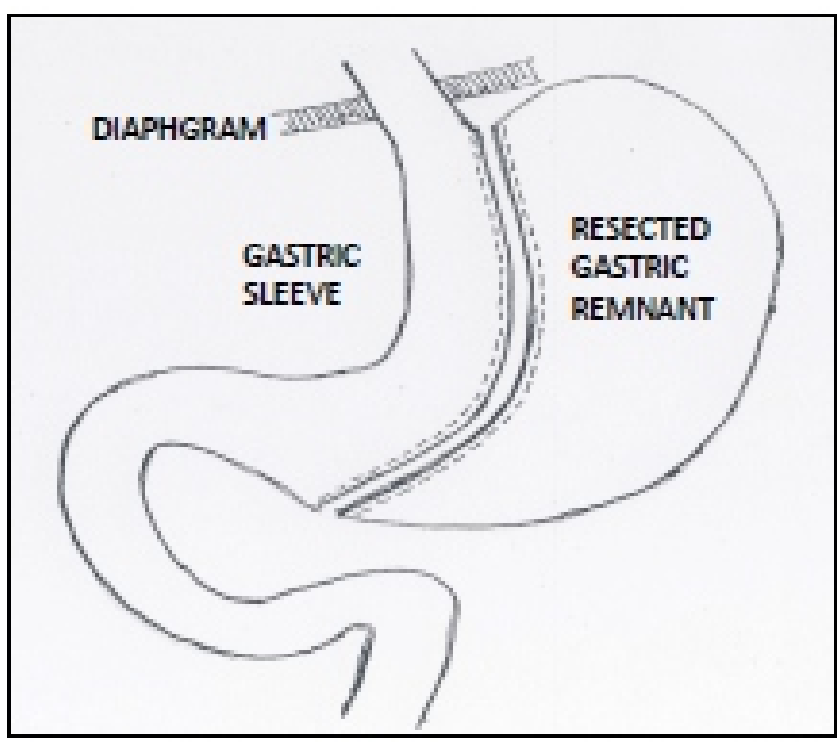

Figure 3. Laparoscopic sleeve gastrectomy (LSG)

Although initially it was part of first stage of a duodenal switch, now it is considered as an effective stand-alone restrictive procedure. LSG is currently the fastest growing bariatric procedure, and in 2011, accounted for 28 percent of all bariatric procedures performed worldwide [37].

It is technically easier to perform and is a favoured by patients as it is less drastic. The small tubular stomach is resistant to stretching and has fewer ghrelin-producing cells. After LSG, gastric emptying is accelerated in the majority of patients but dumping is minimized due to the preservation of the antrum, pylorus and the duodenal continuity. Some patients may develop mineral and vitamin deficiency and should be considered in the dietary management after surgery as it could play a significant role in the outcome [38]. After LSG, weight loss is usually dramatic, but dilatation of the gastric 
tube, over time, can lead to weight gain. Studies show LSG to be safe and effective with 3-year excess weight loss (EWL) of 77.5 percent and $6+$ year of 53.3 percent [39]. A systematic review of 27 studies (673 patients) after LSG showed the resolution of diabetes in 66 percent and improvement in another 27 percent with a mean decrease in glycosylated hemoglobin of 1.7 percent [40]. The two common complications after LSG are staple-line bleeding and anastomotic leakage. A recent analysis of 42 selected papers showed a very low morbidity $(<10 \%)$, mortality $(<1 \%), 20$ to 31 percent prevalence of gastro esophageal reflux and the possibility of regaining weight after 5 years in 15 to 75 percent of individuals following this procedure [41].

\section{Comparison of surgical procedures}

A systematic review evaluating the clinical outcomes for LABG and RYGB involving 14 comparative studies showed excess weight loss at 1 year was consistently greater for RYGB than LABG (median difference, 26 percent; range, 19-34 percent; $\mathrm{P}<001)$. Resolution of comorbidity was greater after RYGB with resolution of diabetes noted in 78percent versus 50 percent. Weight loss outcomes strongly favored RYGB over LABG [42]. The reduction in BMI and most weight-related comorbidity after LSG is between those of LAGB and RYGB [43]. Although current evidence favours RYBG, it is incumbent on all surgeons to be familiar with other bariatric operations.

\section{Uncommon procedures}

\section{Jejunoileal bypass}

Is purely a malabsorptive operation and was popular in the 1970s. With the evolution of bariatric surgery, it has been replaced by other procedures due to significant morbidity and mortality rates [44].

\section{Vertical banded gastroplasty(VBG)}

VBG was the first purely restrictive procedure for treatment of obesity and was introduced in the early 1970s. The upper part of the stomach is partitioned by a vertical staple line with a tight outlet wrapped by a prosthetic mesh or band.(Figure 4) The procedure is rarely undertaken now as it has very poor long-term weight loss.

\section{Bilio-pancreatic diversion (BPD)}

BPD consists of a partial gastrectomy and

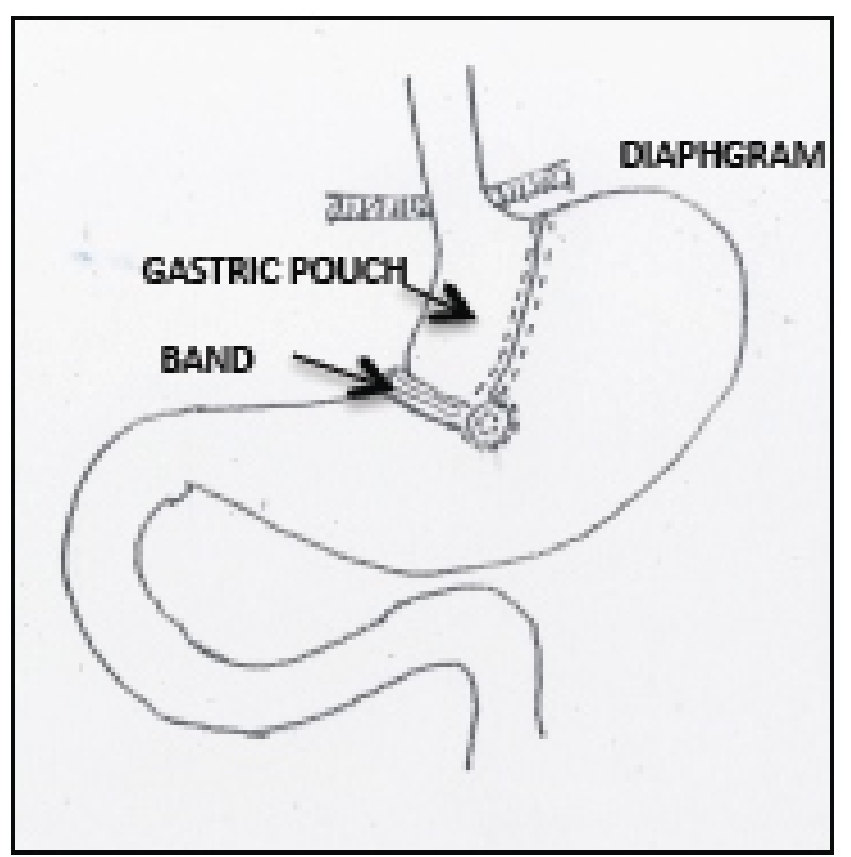

Figure 4 . Vertical banded gastroplasty (VBG)

gastroileostomy with a long segment of roux limb and a short common channel. This procedure may result in anaemia, diarrhoea, and stomal ulceration. It is a technically difficult operation and known to cause fat and protein malabsorption. As such, it has not been widely accepted.

\section{Bilio-pancreatic diversion (BPD) with duodenal switch (DS)}

Originally described by Scopinaro in 1979 to replace jejunoileal bypass [45], BPD with DS is a combination of restrictive and malabsorptive weight loss mechanisms and is performed in the super obese (BMI $>50$ ) patient or in some cases as a revisional procedure for failed weight loss. Bilio-pancreatic diversion (BPD) involves sleeve gastrectomy, ileal division (enteric limb) $250 \mathrm{~cm}$ proximal to the ileocaecal junction and anastomosis of the distal ileal limb to the stomach pouch. The proximal bilio-pancreatic limb is joined to the distal ileum $50 \mathrm{~cm}$ proximal to the ileo-caecal junction to form a common channel. (Figure 5)

A recent systematic review and meta-analysis confirmed weight loss and diabetes resolution were greatest for patients undergoing biliopancreatic diversion with duodenal switch, followed by gastric bypass, and was least for banding procedures [46]. Another randomized trial conducted to evaluate perioperative (30-day) safety and 1-year results of RYGB and DS showed comparable results with regard 


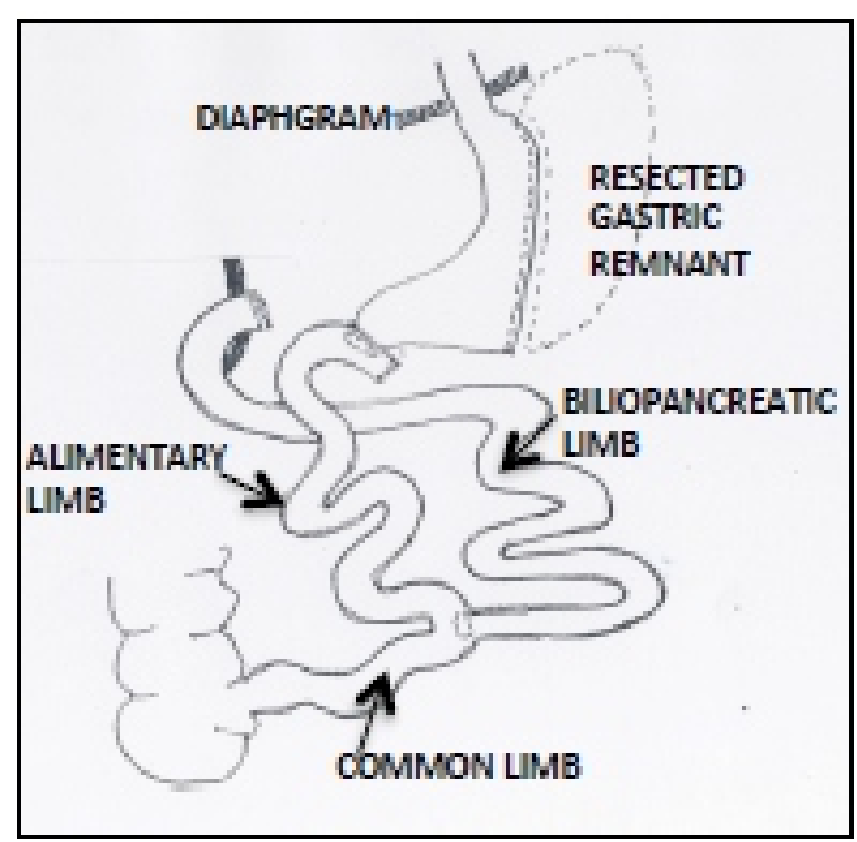

Figure 5. Bilio-pancreatic diversion (BPD) with duodenal switch (DS)

to safety [47]. DS also provided greater weight loss in the super-obese patients [48].

\section{Conclusion}

Bariatric surgery is now widely accepted as the most effective treatment for

long-term weight loss. The definition of obesity and the criteria for bariatric surgery in the Asian subcontinent is not similar to other parts of the world. It is recommended that a dedicated well trained multi disciplinary team, committed to long-term patient management and follow-up, must be involved in the care of these patients. Bariatric surgery should be carried out in surgical units with adequate facilities and infrastructure and practice must follow a standard protocol for bariatric services. This is cost- effective and ensures a safe and a successful outcome.

References:

1. World Health Organization. World Health Statistics 2013. http://www.who.int/mediacentre/factsheets/fs311/en/

2. Wu Y. Overweight and obesity in China. British Medical Journal 2006; 333:362-363.

3. Aekplakorn W, Chaiyapong Y, Neal B. et al., Prevalence and determinants of overweight and obesity in Thai adults: results of the Second National Health Examination Survey. Journal of the Medical Association of Thailand 2004; 87:
685-693.

4. Ramachandran A, Mary S, Yamuna A, Murugesan N, Snehalatha C. High prevalence of diabetes and cardiovascular risk factors associated with urbanization in India. Diabetes Care 2008; 31: 893-898.

5. Alberti KGMM, Zimmet P, Shaw J. Metabolic syndrome - a new world-wide definition. A consensus statement from the International Diabetes Federation Diabetic Medicine. 2006; 23; 469-480.

6. Katulanda P, Jayawardena MA, Sheriff MH, Constantine GR, Matthews DR. Prevalence of overweight and obesity in Sri Lankan adults. Obes Rev 2010; 11:751-756.

7. Wijewardene K, Mohideen M, Mendis S, Fernando D, Kulathilaka T, Weerasekara D, Uluwitta P: Prevalence of hypertension, diabetes and obesity: baseline findings of a population based survey in four provinces in Sri Lanka. Ceylon Med J 2005; 50:62.

8. Mark AL. Dietary therapy for obesity: an emperor with no clothes. 4 Hypertension 2008;51:1426-34.

9. Gloy VL, Briel M, Bhatt DL, Kashyap SR, Shauer PR, Mingrone $G$ et al. Bariatric surgery versus non-surgical treatment for obesity: a systematic review and meta-analysis of randomised controlled trials. BMJ 2013; 34:5934.

10. Mingrone G, Panunzi S, De Gaetano A et al. Bariatric surgery versus conventional medical therapy for Type 2 diabetes. N Engl J Med 2012;366:1577-85.

11. Sjostrom L. Review of the key results from the Swedish Obese Subjects (SOS) trial - a prospective controlled intervention study of bariatric surgery. J Intern Med. 2013; 273:219-34. doi: 10.1111/joim.12012.

12. WHO expert consultation appropriate body-mass index for Asian populations and its implications for policy and intervention strategies. Lancet 2004;363(9403):157.

13. Lakdawala M, Bhasker A. Report: Asian consensus meeting on metabolic surgery. Recommendations for the use of bariatric and gastrointestinal metabolic surgery for treatment of obesity and type II diabetes mellitus in the Asian population. Obes Surg 2010;20:929-936.

14. Bult MJF, Dalen TV, Muller AF. Surgical treatment of obesity. European Journal of Endocrinology 2008; 158; 135-145. doi: 10.1530/EJE-07-0145.

15. Abilés V, Rodríguez-Ruiz S, Abilés J, Mellado C, García 
A, Pérez de la Cruz A, Fernández-Santaella MC. Psychological characteristics of morbidly obese candidates for bariatric surgery. Obes Surg. 2010; 20:161-7. doi:10.1007/s11695-008-9726-1.

16. Nepomnayshy D, Hesham W, Erickson B et al. Sleep apnea: is routine preoperative screening necessary? Obes Surg 2013;23:287.

17. Brodsky JB, Lemmens HJ, Brock-Utne JG, Vierra M, Saidman LJ. Morbid obesity and tracheal intubation. Anesth Analg, 2002; 94: 732-736.

18. Vilos GA, Ternamian A, Dempster J, Laberge PY. Laparoscopic entry: a review of techniques, technologies, and complications. J Obstet Gynaecol Can. 2007; 29:433-65.

19. Michael I. Horowitza and I. Michael Leitman. Risk Factors for the development of incisional hernia following roux-en-Y gastric bypass surgery. The Open Surgery Journal 2008; 2: 15-17.

20. Hutter MM, Randall S, Khuri SF, Henderson WG, Abbott WM, Warshaw AL. Laparoscopic versus open gastric bypass for morbid obesity. A multicenter, prospective, risk-adjusted analysis from the national surgical quality improvement program. Ann Surg. May 2006; 243: 657-666. doi: 10.1097/01.sla.0000216784.05951.0b.

21. Nguyen NT, Masoomi H, Magno CP et al. Trends in use of bariatric surgery 2003-2008. J Am Coll Surg 2011;213:261.

22. Lomanto D, Lee WJ, Goel R et al. Bariatric surgery in Asia in the last 5 years (2005-2009). Obes Surg. 2012; 22: 502-6.

23. El Shobary H, Backman S, Christou N, Schricker T. Use of critical care resources after laparoscopic gastric bypass: effect on respiratory complications. Surg Obes Relat Dis. 2008; 4: 698.

24. Lidor AO, Moran-Atkin E, Stem M, Magnuson TH, Steele KE, Feinberg R, Schweitzer MA. Hospital-acquired conditions after bariatric surgery: we can predict, but can we prevent? Surg Endosc (published on-line 17th April) doi: 10.1007/s00464-014-3602-y.

25. El Chaar M, Claros L, Ezeji GC, Miletics M \& Stoltzfus J. Improving outcome of bariatric surgery: Best practices in an accredited surgical center. Obes Surg 2014; 24:1057-1063. doi: 10.1007/s11695-014-1209.

26. Henrikson V. [Kan tunnfarmsresektion forsvaras som terapi mot fettsot? Nordisk Medicin 1952;47:744]. Can small bowel resection be defended for therapy for obesity? Obes Surg. 1994; 4:54-5.

27. Wolfe BM, Morton JM. Weighing in on bariatric surgery: procedure use, readmission rates, and mortality. JAMA 2005; 294:1960-1963.

28. de Fatima Haueisen Sander Diniz M, de Azeredo Passos VM, Diniz MT. Gut brain communication: how does it stand after bariatric surgery? Curr Opin Clin Nutr Metab Care 2006; 9:629-636.

29. O'Brien PE. Laparoscopic adjustable gastric banding: a real option for a real problem. ANZ J Surg 2003; 73:562.

30. Chapman AE, Kiroff G, Game P et al. Laparoscopic adjustable gastric banding in the treatment of obesity: a systematic literature review. Surgery 2004; 135:326-351.

31. O'Brien PE, MacDonald L, Anderson M, Brennan L, Brown WA. Long-term outcomes after bariatric surgery: fifteen-year follow-up of adjustable gastric banding and a systematic review of the bariatric surgical literature. Ann S u r g. $2013 ; \quad 257: 87-94$. d o i : 10.1097/SLA.0b013e31827b6c02.

32. Muiller MK, Attigah N, Wildi S, Hahnloser D, Hauser R, Clavien PA, Weber M. High secondary failure rate of rebanding after failed gastric banding. Surg Endosc. 2008; 22:448-453.

33. DeMaria EJ. Bariatric surgery for morbid obesity. N Engl J Med 2007;356:2176-2183.

34. Fobi MA, Lee H, Holness R, et al. Gastric bypass operation for obesity. World J Surg. 1998; 22: 925-935.

35. Korner J, Bessler M, Cirilo LJ et al. Effects of Roux-en-Y gastric bypass surgery on fasting and postprandial concentrations of plasma ghrelin, peptide YY, and insulin. J Clin Endocrinol Metab 2005; 90:359.

36. Jacobsen SH, Olesen SC, Dirksen C et al. Changes in gastrointestinal hormone responses, insulin sensitivity, and beta-cell function within 2 weeks after gastric bypass in nondiabetic subjects. Obes Surg 2012;22:1084.

37. Buchwald H, Oien DM. Metabolic/bariatric surgery worldwide 2011. Obes Surg 2013;23:427-36.

38. Braghetto I, Davanzo C, Korn O, Csendes A, Valladares H, Herrera E, Gonzalez P, Papapietro K. Scintigraphic evaluation of gastric emptying in obese patients submitted to sleeve gastrectomy compared to normal subjects. Obes Surg. 
$2009 ; 19: 1515$.

39. Himpens J, Dobbeleir J, Peeters G. Long-term results of laparoscopic sleeve gastrectomy for obesity. Ann Surg. 2010; 252:319-24. doi: 10.1097/SLA.0b013e3181e90b31.

40. Gill RS, Birch DW, Shi X, Sharma AM, Karmali S. Sleeve gastrectomy and type 2 diabetes mellitus: a systematic review. Surg Obes Relat Dis 2009;6:707-13.

41. Braghetto I, Csendes A, Lanzarini E, Papapietro K, Cárcamo C, Molina JC. Is laparoscopic sleeve gastrectomy an acceptable primary bariatric procedure in obese patients? Early and 5-year postoperative results. Surg Laparosc Endosc Percutan Tech. 2012; 22:479-86. doi: 10.1097/SLE.0b013e318262dc29.

42. Tice JA, Karliner L, Walsh J, Petersen AJ, Feldman MD. Gastric banding or bypass? A systematic review comparing the two most popular bariatric procedures. Am J Med. 2008; 121:885-93. doi: 10.1016/j.amjmed.2008.05.036.

43. Hutter MM, Schirmer BD, Jones DB, et al. First report from the American College of Surgeons Bariatric Surgery Center Network: laparoscopic sleeve gastrectomy has morbidity and effectiveness positioned between the band and the bypass. Ann Surg 2011; 254:410-20.

44. Buchwald H, Buchwald JN. "Evolution of operative procedures for the management of morbid obesity 1950-2000,"Obesity Surgery 2000; 12: 705-717.

45. Scopinaro N, Gianetta E, Civalleri D, Bonalumi U, Bachi $\mathrm{V}$ Biliopancreatic by-pass for obesity. II. Initial experience in man. British Journal of Surgery 1979; 66: 618-620.

46. Buchwald H, Estok R, Fahrbach K. et al. Weight and type 2 diabetes after bariatric surgery: systematic review and metaanalysis. The American Journal of Medicine 2009; 122: 248-256.

47. Sovik TT, Taha O, Aasheim ET et al. Randomized clinical trial of laparoscopic gastric bypass versus laparoscopic duodenal switch for superobesity. British Journal of Surgery 2010; 97: 160-166.

48. Nelson DW, Blair KS, Martin MJ. Analysis of obesityrelated outcomes and bariatric failure rates with the duodenal switch vs. gastric bypass for morbid obesity. Arch Surg 2012; $147: 847$ 